\title{
Low grade Endometrial Stromal Sarcoma of uterine corpus, a clinico-pathological and survey study in I 4 cases
}

\author{
Tahereh Ashraf-Ganjoei, Nadereh Behtash*, Mamak Shariat and \\ Asamosadat Mosavi
}

Address: Gynecologic Oncology Department, Vali Asr Hospital, Keshavarz Blvd., Tehran 14194, Iran

Email: Tahereh Ashraf-Ganjoei - tashrafganjoei@yahoo.com; Nadereh Behtash* - nadbehtash@yahoo.com; Mamak Shariat - valrec2@yahoo.com; Asamosadat Mosavi - valrec2@yahoo.com

* Corresponding author

Published: 09 August 2006

World Journal of Surgical Oncology 2006, 4:50 doi:10.1 I86/1477-78/9-4-50

This article is available from: http://www.wjso.com/content/4/I/50

(c) 2006 Ashraf-Ganjoei et al; licensee BioMed Central Ltd.

This is an Open Access article distributed under the terms of the Creative Commons Attribution License (http://creativecommons.org/licenses/by/2.0), which permits unrestricted use, distribution, and reproduction in any medium, provided the original work is properly cited.
Received: 0I March 2006

Accepted: 09 August 2006

\begin{abstract}
Background: Endometrial stromal sarcoma (ESS) is a rare disease with probably less than 700 new cases in the USA or Europe per year. The aim of this study was to evaluate the behavior of lowgrade endometrial stromal sarcoma (LGESS) in relation to their clinical and pathological features and to identify possible prognostic factors.

Patients and methods: Fourteen patients with histologically proven ESS were included in the analysis. Endometrial stromal sarcoma is characterized by proliferations composed of cells with Endometrial stromal cell differentiation. Low-grade endometrial stromal sarcoma has an infiltrating margin and typically show extensive worm-like vessel invasion.

Results: The median age was $44.35 \pm 6$ years. The most common presenting symptom was vaginal bleeding, occurring in twelve patients (86\%). Diagnosis was made through Fractional dilatation and curettage in four patients (28.5\%). Eight patients had a total abdominal hysterectomy and salpingoophorectomy (57\%). Radiotherapy as adjuvant therapy was administered to four patients $(28.5 \%)$. The median follow-up time was 45.6 months (range 24-84). The median overall survival of the 14 patients was $45.35 \pm 21$ months (range 20-83). Three of 14 patients demonstrated a recurrence of disease at 9,72 , and 96 months respectively. The recurrent diseases were treated with surgery, chemotherapy, and radiotherapy. No patient died of the disease. Clinico-pathological parameters did not significantly differ between patients with and without recurrence, but patients with no myometrial invasion and low mitotic count $<=5 / \mathrm{HPF}$ showed longer disease-free survival.
\end{abstract}

Conclusion: Five-year survival rate was $93 \%$. Survival probabilities were calculated by the product limit method of Kaplan and Meier that showed, patients with no myometrial invasion and low mitotic count $<=5 / \mathrm{HPF}$ have longer disease-free survival, but $P$ value was not significant.

\section{Background}

Endometrial Stromal Sarcomas (ESSs) are very rare malignant tumors that constitute approximately $10 \%$ of all uterine sarcomas but only around $0.2 \%$ of all uterine malignancies [1]. The annual incidence of ESS is 1-2 per million women accounting for 400 to 700 new cases each year in Europe [2]. 
ESS can be mistaken for leiomyoma. Its clinical recognition may be difficult, and the diagnosis is often made postoperatively after histological examination $[3,4]$. The typical gross appearances of ESS are a single nodule, multiple solid-cystic masses, and a poorly demarcated lesion with occasional cystic degeneration or rarely cystic multilocular lesion [5]. There are three types of endometrial stromal tumors: endometrial stromal nodule, low-grade ESS (LGESS), and high-grade ESS (HGESS). Only the nature of the margin, histologically differentiate LGESS from stromal nodule. The division of endometrial stromal sarcomas into low-grade and high-grade categories has fallen out of favor, and the term endometrial stromal sarcomas now considered best restricted to neoplasms that were formally to as low-grade endometrial stromal sarcomas [6]. High-grade tumors without recognizable evidence of a definite endometrial stromal phenotype are now termed endometrial sarcomas [7].

The pathogenesis of these lesions remains unknown, but exposure to tamoxifen and unopposed estrogens has been implicated in some cases [8].

Uterine sarcomas most often affect postmenopausal women [9]. Women with LGESS are younger than women with other uterine sarcomas, with a median age between 45 and 57 years and, generally do not have the usual risk factors for endometrial cancer. Symptoms at presentation include abnormal vaginal bleeding, progressive menorrhagia, and abdominal pain. While often indolent in behavior, ESS is malignant, and up to $30 \%$ of women with low-grade ESS have extra uterine disease at presentation.

Surgery is fundamental in LGESS as other sarcoma. Management and treatment generally consists of total abdominal hysterectomy and bilateral salpingo-oophorectomy. Due to the high recurrence risk even with localized tumors, many clinicians advocate use of adjuvant chemotherapy, radiation therapy, and/or hormone therapy to suppress tumor growth [4]. There is no firm evidence from a prospective study that adjuvant chemotherapy or radiation therapy is of substantial benefit for patients with uterine sarcoma. Postoperative pelvic radiotherapy reduces local recurrence but has not been consistently shown to prolong survival.

Progestin therapy has been reported to reduce the risk of recurrence when used in the adjuvant setting. Most women with LGESS undergo bilateral salpingo-oophorectomy as part of primary treatment but estrogen also can be produced by extraovarian sources.

These tumors typically have an indolent growth with a tendency for late recurrence [6]. Pelvic or abdominal recurrences in stage I disease develop in one-third to onehalf of patients [10].

The aim of this study was to evaluate the clinical outcome and the behavior of LGESS in relation to its clinical and pathological features.

\section{Patients and methods}

This study includes 14 patients with histologically proven low-grade endometrial stromal sarcoma treated at of Gynecologic Oncology Department of the Vali-Asr University Hospital, Tehran, Iran, between 1999 to 2005 . Hospital records and available histological material for each patient were reviewed retrospectively. Slides from each patient were reexamined to confirm the diagnosis.

Patients with a diagnosis of high-grade endometrial stromal sarcoma were not included. Demographic information, pathologic, and treatment information were collected from the clinic and hospital charts. All had primary surgical management. Eight patients underwent total abdominal hysterectomy and salpingo-oophorectomy, and three patients underwent subtotal hysterectomy and salpingo-oophorectomy. In one patient, subtotal hysterectomy without salpingo-oophorectomy was performed. They had regular follow-up visits until the end of study.

The end point of 5-year survival was used for analysis. Survival probabilities were calculated by Kaplan and Meier method. Correlation between recurrence and clinicopathological parameters (myometrial invasion, mitotic count) was tested using the Fisher Exact test. P values of less than 0.05 were considered statistically significant.

\section{Results}

Fourteen patients with LGESS were identified at our institution from 1999 to 2005 . The median age was $44.35 \pm 6$ years (range 33-52). The mean parity of the patients was 4.4 (range 0-8). The most common presenting symptom was vaginal bleeding, occurring in twelve patients $(86 \%)$ while other features such as pelvic mass and acute abdominal pain were observed in $1(7 \%)$ and $1(7 \%)$ patients, respectively (table 1). Clinical impression in four patients $(29 \%)$ was uterine myoma.

Fractional dilatation and curettage (FD\&C) was performed in four patients presenting with abnormal uterine bleeding (AUB). Diagnosis was made through FD\&C in four patients. The other 10 patients were diagnosed by hysterectomy. All the histological slides were reexamined by the same pathologist.

Eight patients had a total abdominal hysterectomy and four patients had a subtotal hysterectomy as part of their 
Table I: patient characteristics.

\begin{tabular}{|c|c|c|c|c|c|c|c|c|c|}
\hline No & Age & Parity & Symptom & $D \& C$ & Type of Operation & Myometrial Invasion & Mytotic Count & Irradiation & Recurrence \\
\hline $\mathbf{I}$ & 49 & 2 & AUB & Yes & TAH\&BSO & Low & $=<5 / 1 \mathrm{OHPF}$ & Yes & \\
\hline 2 & 42 & 6 & AUB & Yes & TAH\&BSO & Deep & $>5 / 10 \mathrm{HPF}$ & Yes & \\
\hline 3 & 51 & 3 & AUB & No & TAH\&RSO & No & $=<5 / 10 \mathrm{HPF}$ & Yes & \\
\hline 4 & 52 & 5 & AUB & No & TAH\&RSO & & $>5 / 10 \mathrm{HPF}$ & No & \\
\hline 5 & 38 & 7 & AUB & Yes & & & & & \\
\hline 6 & 37 & 3 & Pelvic Mass & No & Trachelectomy \& RSO & No & $=<5 / 10 \mathrm{HPF}$ & Yes & Yes \\
\hline 7 & 48 & 8 & AUB & No & $\mathrm{TAH}$ & & & No & Yes \\
\hline 8 & 33 & 5 & AUB & No & TAH\&BSO & No & $>5 / 10 \mathrm{HPF}$ & No & Yes \\
\hline 9 & 44 & Virgin & AUB & No & TAH\&BSO & No & & & \\
\hline 10 & 48 & 3 & AUB & No & subTAH\&BSO & No & $=<5 / 10 \mathrm{HPF}$ & No & \\
\hline I I & 38 & 4 & Acute Abdomen & No & subTAH & No & & & \\
\hline 12 & 50 & I & $A \cup B$ & No & subTAH\&BSO & No & $=<5 / 10 \mathrm{HPF}$ & No & \\
\hline 13 & 48 & 8 & AUB & Yes & TAH\&BSO & Low & $=<5 / 10 \mathrm{HPF}$ & No & \\
\hline 14 & 43 & 7 & AUB & No & subTAH\&BSO & No & $=<5 / 10 \mathrm{HPF}$ & No & \\
\hline
\end{tabular}

AUB: Abnormal uterine bleeding; TAH: total abdominal hysterectomy; HPF: high power field; BSO: Bilateral salpingooopherectomy; RSO: Residual salpingooopherectomy

initial surgical treatment. One patient underwent trachelectomy following the previous subtotal hysterectomy. Radiotherapy as adjuvant therapy was administered to four patients $(29 \%)$.

The median follow-up time was 45.6 months (range 2484 ). Five-year survival rate was $93 \%$. The median overall survival of the 14 patients was $45.35 \pm 21$ months (range 20-83). Only one patient recurred at 9 months. Two of 14 patients demonstrated a recurrence of disease at 6 years, and 8 years respectively (table 2 ). Recurrent disease in pelvic was treated by combination chemotherapy and surgery in one patient. The second patient with recurrence in pelvic and lung received combination chemotherapy and external radiotherapy. In the third patient, recurrence in vagina and lung was treated with combination chemotherapy only. No patient died of the disease. Twelve patients are alive without disease and two alive with disease.

Five-year survival rate was93\%. Survival probabilities were calculated by the product limit method of Kaplan and Meier that showed, patients with no myometrial inva- sion and low mitotic count $<=5 /$ HPF have longer diseasefree survival (fig 1 and fig 2 ), but $P$ value was not significant.

\section{Discussion}

ESS are very rare malignant tumors that make up approximately $10 \%$ of all uterine sarcomas but only around $0.2 \%$ of all uterine malignancies [11].

ESS are divided in low and high-grade tumors according to cell morphology and mitotic count [6], Boardman $\mathrm{CH}$, et al defined low-grade ESS from high-grade ESS by the cellular uniformity, less frequent mitosis ( $<3$ per 10 highpower fields versus $>10$ ), and lack of hemorrhage and necrosis [3]. However, there are controversies surrounding the separation of endometrial stromal sarcomas into high and low grade based on mitotic activity [12]and at present, mitotic counts are no longer used to differentiated high-grade from low-grade lesions [7]. Accordingly, several authors have concluded that two separate disease entities exist and, respectively, that HGESS should be regarded as an undifferentiated sarcoma or as a unique

Table 2: Recurrent Cases

\begin{tabular}{|c|c|c|c|c|c|}
\hline \multirow[t]{2}{*}{ No of patients } & \multirow[t]{2}{*}{ Disease-Free survival } & \multirow[t]{2}{*}{ Sites of recurrence } & \multicolumn{3}{|c|}{ Treatment of Recurrence } \\
\hline & & & Chemotherapy & Irradiation & surgery \\
\hline 6 & 9 months & Pelvic and lung & Yes(first) & Yes & No \\
\hline 7 & 8 years & Vagina and lung & Yes & No & No \\
\hline 8 & 6 years & pelvic & Yes & No & Yes(first) \\
\hline
\end{tabular}




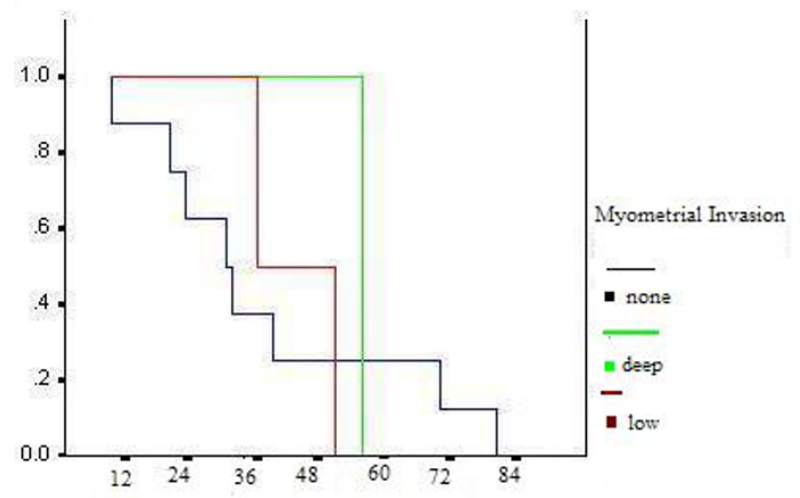

\section{Figure I}

Survival of patients with LGESS based on myometrial invasion.

type of high-grade uterine sarcoma (e.g. carcinosarcoma without any detectable carcinoma portion) [13].

Low-grade endometrial stromal sarcoma (LGESS) has an infiltrating margin and typically shows extensive wormlike vessel invasion [6].

Most patients are in the age range of 42 to 53 years. More than half the patients are premenopausal. Young women and girls may be affected. In this study, $79 \%$ of patients were premenopausal.

Abnormal vaginal bleeding is the most common presenting symptom, and abdominal pain and uterine enlarge-

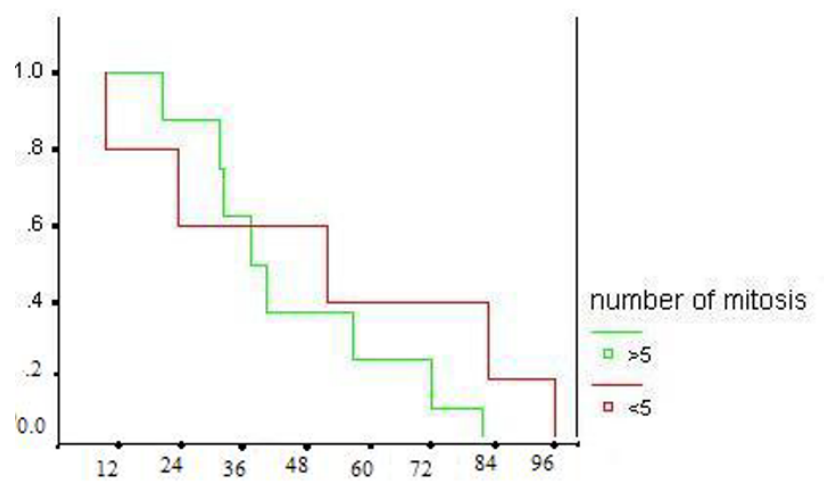

Figure 2

Survival of patients with LGESS based on number of mitosis. ment may occur $[9,7]$. We showed abnormal vaginal bleeding in $86 \%$ of the patients. Clinical impression in four cases was uterine myoma $(28.5 \%)$ and one patient had presented with severe abdominal pain.

The median follow-up time was 45.6 months (range 2484 ). Five-year survival rate was $93 \%$. In this study, the median overall survival of the 14 patients was $45.35 \pm 21$ months (range 20-83).

Although the bulk of the tumor is almost always intramyometrial [14], most endometrial stromal sarcomas involve the endometrium, and uterine curettage usually leads to diagnosis [7]. In our study, the diagnosis in four patients $(28.5 \%)$ was made through D\&C. The other 10 patients were diagnosed by hysterectomy (71\%). Surgery has always been described as the most effective treatment in LGESS as other uterine sarcomas. Primary surgery was performed in 13 patients in our series. The one patient refused from any treatment such as surgery.

The efficacy of adjuvant therapy in patients with ESS is still not proven [15]. In our study radiotherapy as adjuvant, therapy was administered to four patients $(28.5 \%)$, but one of them recurred at 9 months.

Although LGESS behavior is relatively indolent, late recurrence and distant metastases may occur [14]. The risk of recurrence is thought to be as high as $50 \%$, although these tumors are usually slow growing and recurrences occur late. In one large series, the interval before recurrence varied from 3 months to 23 years, with a median interval of 3 years. In the largest clinico-pathologic study to date on ESS, the median time between hysterectomy and relapse was 5.4 years and 9 month for stages 1 and 3-4, respectively [16]. We showed only one recurrence at 9 months, but two recurrences occurred at 6 and 8 years respectively.

In Brunisholza study, the recurrent disease mainly spread to the pelvis, lower genital tract, lungs, and rarely to other site [17]. Recurrence sites in our patients were vagina, pelvis, and lung.

Prolonged survival and even cure are common after surgical resection of recurrent or matastatic lesions [7]. One of our patients is alive 3 years without disease after resection of vaginal metastasis and chemotherapy.

Uterine sarcomas have a poor prognosis, and survival is much worse than that reported for endometrial adenocarcinoma, with an overall survival of less than $50 \%$ at 2 years, even when presenting at an early stage [18]. A higher survival probability for patients with LGESS compared to other uterine sarcoma is often reported [19]. In this study, five-year survival rate was $93 \%$. 
Prognostic factors in patients with ESS are still discussed controversially [11]. The negative prognostic influence of a high mitotic count was revealed in previous studies [20]. In the present study, survival probabilities were calculated by the product limit method of Kaplan and Meier that showed, patients with no myometrial invasion and low mitotic count $<=5 / \mathrm{HPF}$ have longer disease-free survival, but $\mathrm{P}$ value was not significant.

\section{Conclusion}

In summary, we found not significant association between mitotic count, myometrial invasion and risk of recurrence. The large variation in pathologic characteristics and in treatment policies, combined with the scarcity of patients, has meant that in the past, there has been a general feeling that there is insufficient information on optimal managements and their influence on tumor behavior. The difficulty in obtaining information on tumor behavior and best treatment has led different authors to study of the prognostic factors. Additional studies on a larger group of patients allowing multi analysis are necessary to be better able to predict the prognosis of patients with ESS and to define the exact role of adjuvant therapy.

\section{Competing interests}

The author(s) declare that they have no competing interest

\section{Authors' contributions}

TAG participated in the design of the study and participated in drafting the manuscript.

NB carried out the surgery and helped to draft the manuscript.

MS participated in drafting the manuscript.

AM carried out the chemotherapy and follow-ups.

All authors read and approved the final manuscript.

\section{References}

I. Boardman $\mathrm{CH}$, Webb MJ, Jefferies JA: Low-Grade Endometrial Stromal Sarcoma of the Ectocervix after Therapy for Breast Cancer. Gynecologic Oncology 2000, 79:120-123.

2. Pink D, Lindner T, Mrozek A, Kretzschmar A, Thuss-Patience PC, Dörken B, Peter Reichardt : Harm or benefit of hormonal treatment in metastatic low-grade endometrial stromal sarcoma: Single center experience with 10 cases and review of the literature. Gynecol Oncol 2006, 101:464-469.

3. Mesia AF, Demopoulos I: Effects of leuprolide acetate on lowgrade endometrial stromal sarcoma. Am J Obstet Gynecol 2000, 182: II40-II4I.

4. Husseiny GE, Bareedy NA, Mourad WA, Mohamed G, Shoukri M, Subhi J: Prognostic factors and treatment modalities in uterine sarcoma. Am J Clin Oncol 2002, 25:256-260.

5. Pekindil G, Tuncyurek O, Orguc S, Inceboz U, Kandiloglu AR, Caglar $\mathrm{H}$ : A case of endometrial stromal sarcoma with curvilinear calcification. Gynecologic Oncology 2005, 98:318-32I.
6. Shafi M, Luesley DM, Jordan JA: Gynecological Oncology Churchil Livingstone, UK; 200I:I20-I2I.

7. Berkowitz RS, Goldstein DP: Uterine cancer. In Practical Gynecologic Oncology 4th edition. Edited by: Berek JS, Hacker NE. Williams \& Wilkins; 2005:43I-432.

8. Feeley KM, Burton JL, Wells M: A diagnostic approach to endometrial biopsies: selected topics. Current Diagnostic Pathology 2000, 6:13-20.

9. Livi L, Paiar F, Shah N, Blake P, Villanucci A, Amunni G: Uterine sarcoma: twenty-seven years of experience. Int J Radiat Oncol, Biol, Phys 2003, 57:1366-1373.

10. Spano JP, Soria JC, Kambouchner M, Piperno-Neuman S, Morin F, Morere JF, Martin A, Breau JL: Long term survival of patients given hormonal therapy for metastatic endometrial stromal sarcoma. Med Oncol 2003, 20:87-93.

II. Liokumovich P, Goldberg I, Davidson B, Gotlieb WH, Zahavi T, Benbaruch G, Kopolovic J: Expresion of metalloproteinases endometrial stromal sarcoma: immunohistochemical study using image analysis. J Clin Pathol 1999, 52:198-202.

12. Fadare O, McCalip B, Rajan Mariappan R, Hileeto D, Parkash V: An endometrial stromal tumor with osteoclast-like giant cells: Expanding the morphological spectrum. Ann Diag Pathol 2005, 9:160-165.

13. Amant F, Vergote I, Moerman P: The classification of a uterine sarcoma as high-grade endometrial stromal sarcoma should be abandoned. Gynecol Oncol 2004, 95:4I 2-4I3.

14. Stadsvold JL, Molpus KL, Baker JJ, Michael K, Remmenga SW: Case Report-Conservative management of a myxoid endometrial stromal sarcoma in a 16-year-old nulliparous woman. Gynecol Oncol 2005, 99:243-245.

15. Gellera MA, Argentaa P, Bradleya W, Dusenberyb KE, Brookera D, Downs LS, Judsona PL, Carsona LF, Boentea MP: Treatment and recurrence patterns in endometrial stromal sarcomas and the relation to c-kit expression. Gynecol Oncol 2004, 95:632-636.

16. Amant F, Moerman P, Cadron I, Neven P, Berteloot P, Vergote I: The diagnostic problem of endometrial stromal sarcoma:report on six cases. Gynecol Oncol 2003, 90:37-43.

17. Brunisholza YJ, Scurryb MJ, Proietto A: Case Report-Endometrial stromal sarcoma resembling adenomyosis and menstrualphase endometrium. Gynecol Oncol 2004, 95:256-259.

18. Rovirosa A, Ascaso, Ordi J, Abellana, Arenas M, Lejarcegui JA, Pahisa J, Puig-Tintore LM, Mellado B, Armenteros B, Iglesias X, Biete A: Is vascular and lymphatic space invasion a main prognostic factor in uterine neoplasms with a sarcomatous component? A retrospective study of prognostic factors of 60 patients stratified by stages. Int J Radiation Oncol Biol Phys 2002, 52:1320-1329.

19. Nardal RR, Kjoerstad K, Stenwing AE, Trope CT: Leimyosarcoma (LMS) and endometrial stromal sarcoma (ESS) of the uterus: a survey of patients treated at the norvegian Radium Hospital I 97 I-1 985. Int ] Gynecol Cancer 1993, 3: I I0-I I 5.

20. Bonder K, Bonder-Alder B, Obermair A, Windbichler G, Petru E, Mayerhofer S, Czerwenka K, Leodolter S, Kainz C, Mayerhofer K: Prognostic parameters in endometrial stromal sarcoma: A clinicopathological study in $3 \mathrm{I}$ patients. Gynecol Oncol 200I, $81: 160-165$

Publish with Bio Med Central and every scientist can read your work free of charge

"BioMed Central will be the most significant development for disseminating the results of biomedical research in our lifetime. "

Sir Paul Nurse, Cancer Research UK

Your research papers will be:

- available free of charge to the entire biomedical community

- peer reviewed and published immediately upon acceptance

- cited in PubMed and archived on PubMed Central

- yours - you keep the copyright
BioMedcentral 